Celestinesca 33 (2009): 255-258 https://doi.org/10.7203/Celestinesca.33.20098

\title{
El estreno mundial y póstumo de la ópera La Celestina de Joaquín Nin-Culmell
}

\author{
(Teatro de la Zarzuela de Madrid)
}

\begin{abstract}
La Celestina. Tragicomedia musical en tres actos.
Música y libreto de Joaquín Nin-Culmell. A partir de La Celestina de Fernando de Rojas y textos de Juan del Encina.

Teatro de la Zarzuela: 19 de septiembre 2008

Dirección Musical: Miguel Ortega

Dirección de Escena: Ignacio García

Escenografía: Domenico Franchi

Vestuario: Lluís Juste de Nin

Reparto: Calisto: Alain Damas / Sempronio: José A. García Quijada / Pármeno: Andrés del Pino / Celestina: Alicia Berri / Areúsa: Carolina Barca / Melibea: Gloria Londoño / Lucrecia: Belén Elvira / Elicia: Soledad Cardoso / Socias: Andrés Bernal; Miguel Ángel Bustamante; Sergio Castelar; Rafa Molina; Xavi Montesinos
\end{abstract}

Celestina es el único personaje de los cuatro mítico-literarios españoles que no disfruta de una larga tradición operística. Sobre Don Quijote ya conocemos óperas en el siglo Xvil y tanto Don Juan como Carmen se han convertido, precisamente gracias a las obras de Mozart y Bizet, en arquetipos de lo español a partir del siglo XIX. No hay ópera sobre Celestina hasta 1902, cuando sale a luz la controvertida obra de Felipe Pedrell, nunca representada de forma completa. ${ }^{1}$ Joaquín Nin-Culmell eligió este

1.- Véase la lista de óperas celestinescas incluida en el artículo de J. T. Snow \& Arno Gimber, «Richard Strauss, Stefan Zweig, Joseph Gregor and the Story of the Celestina Opera that Almost was, with a Bibliographic Appendix of Celestina Operas in the Twentieth Century», Celestinesca 31 (2007):133-164. 
personaje para convertirlo en protagonista de su única pieza operística porque quiso mejorar el modelo de Pedrell. En el Teatro de la Zarzuela de Madrid fue estrenado el día 19 de septiembre de 2008 aún en el centenario de su nacimiento. ${ }^{2}$ Las expectativas eran altas porque de antemano se decía que se trataba de la mayor obra del compositor, escrita ya entre 1956 y 1959 y revisada entre 1985 y 1991 principalmente.

Joaquín Nin-Culmell, de padre cubano-español y madre catalana, había nacido cien años antes en Berlín y estudiado en Barcelona con Conchita Badía que, dato curioso, actuó en el estreno de La Celestina de Pedrell como Melibea. También vivió en París y como músico se le considera alumno de Falla y del mismo Pedrell, con influencias además del impresionismo francés y de su propio padre, Joaquín Nin Castellanos, un compositor en cuya obra tiene una gran presencia la música popular española. Se movía en el entorno de la Generación del 27, relacionándose de manera especial con Federico García Lorca y Pedro Salinas. En 1940 se marchó de Francia a Estados Unidos, consiguió la ciudadanía americana en 1951, y en 2001, tres años antes de su muerte, se le concedió la nacionalidad española.

Quizá el problema de una Celestina operística sea el libreto ya que éste, cuando se basa en un modelo literario, exige siempre una reducción y síntesis de un argumento que en el caso de La Tragicomedia de Calisto y Melibea es extremadamente complejo. Nin comprimió la obra en tres cortos actos - un total de seis escenas más un prólogo sin palabras-que en conjunto dura poco más de una hora. De no ser porque el espectador conoce la trama de antemano, le resultaría difícil reconstruirla. Además de la elipsis, Nin se sirvió de diferentes técnicas de compresión, como por ejemplo los resúmenes de acontecimientos pasados, contados en escena. Se han eliminado personajes importantes, caso de los padres de Melibea y el final de la obra queda abierto, lo que significa la única aportación digamos innovadora al modelo: Melibea sube al muro de la huerta y allí permanece sin que nadie sepa si se suicidará o no.

Las voces de los personajes se distribuyen con cierta coherencia: la protagonista, una mezzosoprano, resulta demoníaca, y su papel exige cierta agilidad para poder hacer frente a las coloraturas de la partitura. Melibea, por otro lado, es una soprano lírica y Calisto un tenor del mismo registro. Sempronio y Pármeno son barítonos, Elicia y Areúsa sopranos, y Lucrecia, la criada, es nuevamente una mezzosoprano. En 1999 Nin-Culmell añadió a la obra un coro que aparece en los dos momentos cruciales de la trama, el primero cuando Celestina consigue concertar la cita entre los

2.- Una vez antes, en Madrid, se planeaba su estreno. La Alterna Ópera, una compañía privada con base en Madrid y San Petersburgo, dirigida por Ana María Iriarte y con dirección musical de Alexis Soriano, tenía intención de estrenar la obra de Nin-Culmell en el Teatro Albéniz en enero del año 2001, con Mabel Perelstein en Celestina (datos de Ópera actual [Barcelona], núm 40 (julio agosto 2000), p. 10). Por razones que desconozco, no se llevó a cabo. 
dos amantes y el segundo al final, entremezclándose con los cantos de Melibea sobre el muro. Son coros comentadores que citan textos de Juan del Encina y remiten a su propia música coral.

Tras el corto prólogo mudo o fragmento instrumental que anticipa el encuentro entre los dos amantes en un lugar público, Calisto cuenta a Sempronio y Pármeno en la primera escena este encuentro y su enamoramiento hacia Melibea. El primero de los criados recomienda a su amo acudir a Celestina - "Conozco una vieja barbuda que se dice Celestina; hechicera astuta, sagaz en cuantas maldades hay; (Insinuante.) el remedio te dará, ella te sanará» ${ }^{3}$ - a la que busca enseguida. Tras su llegada, Pármeno insulta a la vieja sin mayor motivo, actitud que Calisto intenta suavizar y que se ve frenada por la propia Celestina al hablarle de Elicia y de Areúsa. En la segunda escena en casa de la alcahueta, ésta convence a Elicia para que acepte a Pármeno como amante. Después la vieja invoca a Plutón con la intención de que funcione la alcahuetería entre Calisto y Melibea, hechizo que recuerda en sus aspectos musicales a uno de los modelos de Nin, que es El amor brujo de su maestro Manuel Falla.

Tras este primer punto culminante, el segundo acto nos lleva al huerto de Melibea. Lucrecia, desde dentro, habla con Celestina, que se encuentra fuera del muro. Consigue que Melibea la reciba. Le habla de Calisto y concierta sin mayores rodeos una cita para las doce de la noche en la puerta del huerto. Es aquí donde interviene el primer coro: «iTriste amante, sin ventura!, todas te deben llorar, desprovisto de alegría para nunca en ti tornar». En la siguiente escena se produce el encuentro de los dos amantes que confiesan sus sentimientos mutuos de amor. Se citan de nuevo para la noche, Calisto debería entrar en el huerto con una escalera. Y también este segundo acto termina en casa de Celestina, donde la vieja, Elicia, Areúsa, Sempronio y Pármeno celebran el éxito de la alcahuetería. En pocos minutos se emborrachan, comienzan a pelearse por el dinero ganado por la vieja, y los criados de Calisto matan a Celestina.

El tercer acto constituye una sola escena, la del huerto de Melibea. Ella canta una canción catalana (lo que quizá remite al origen de sus padres, unos mercaderes de Barcelona, y el impedimento de su enlace con Calisto, castellano viejo noble) y enseguida llega el deseado a la cita de amor. Pronto se oyen alborotos extramuros, Calisto quiere saber qué sucede y el resultado es su caída y muerte. Melibea canta un aria de lamento (que recoge elementos del monólogo final de Pleberio en la obra literaria y por lo tanto no convencen en boca de una muchacha:

$¡ O$, la más triste de las tristes, tan tarde alcanzado el placer, tan presto venido el dolor! ¡Ay, dolor!, rezando lle-

3.- El texto completo de la obra se puede consultar en la página web del Teatro de la Zarzuela: <http://teatrodelazarzuela.mcu.es/FileUploads/File/libreto_la_celestina(2).pdf> (última consulta 16-12-08). 
van mi bien, mi todo. ¡Muerta, muerta mi alegría! Mi fin es llegado, llegado es mi descanso, llegado es mi alivio, llegada es mi acompañada hora. (Se pasea por el huerto una última vez.) Me acortaron mi esperanza, me acortaron mi gloria, me acortaron mi vida.

Ante la incógnita de si se suicida o no, interviene por segunda vez el coro: «A tal pérdida tan triste [...] buscarle consolación [...] claro está que es traición».

No entro en lo que podría ser una reseña del estreno. ${ }^{4}$ Predominaba aquella noche el aburrimiento y la mediocridad y con ello me refiero tanto a la dirección musical y escénica como a los cantantes (quizá con la excepción de las dos protagonistas femeninas). El mayor problema radica, sin embargo, aparte de la adaptación en libreto de un texto complejo ya expuesto, en la composición misma. Estamos de acuerdo con la opinión de Tomás Marcos (en una conferencia introductoria pronunciada pocos días antes del estreno) de que esta ópera significa una visión más bien historicista, puesto que su música está hecha sobre corrientes antiguas, de Falla a los hermanos Halffter. Nin-Culmell utiliza un lenguaje musical muy consolidado, historificado diríamos, en la música española. La ópera, de haberse estrenado años ha, habría tenido más éxito. Esta Celestina, obra de un compositor musicólogo, presenta como aspecto más logrado la inserción de las dos piezas de Juan del Encina. Es cuando la música se desarrolla de forma ágil, madrigalesca y derivada del villancico, algo que muestra de manera llamativa que su origen no es del todo operístico. Quizá la intención del compositor haya sido ésta: diseñar su obra musical en formas híbridas musicales pensando en lo que tiene de género híbrido literario la Celestina. Desafortunadamente la ópera nos deja con una impresión meramente ecléctica.

Arno Gimber

Universidad Complutense, Madrid

4.- Para ello véase más bien Gonzalo Alonso en La razón del 21 de septiembre 2008 y Tomás Marcos en $E l$ mundo del día siguiente. 